\title{
ANALISA UNJUK KERJA PENINGKATAN TRANSMISI CITRA PADA KANAL WIRELESS MENGGUNAKAN TEKNIK DIVERSITY SELECTION COMBINING
}

\author{
Baharuddin \\ Jurusan Teknik Elektro, Fakultas Teknik, Universitas Andalas \\ e-mail : baharuddin.abbas@ft.unand.ac.id
}

\begin{abstract}
Abstrak - Penelitian ini merupakan simulasi citra terkompresi SPIHT menggunakan teknik diversity selection combining. Citra yang digunakan dikompresi terlebih dahulu dengan teknik kompresi SPIHT setelah didekomposisi wavelet. Pada kanal transmisi diberi pemodelan kanal Rayleigh fading dan AWGN yang akan menyebabkan terjadinya penurunan unjuk kerja sistem secara keseluruhan. Oleh karena itu, untuk memperbaiki unjuk kerja sistem tersebut yaitu dengan meminimalkan efek yang diakibatkan oleh error yang terjadi selama transmisi, maka pada bagian penerima digunakan teknik diversity selection combining yang bekerja pada daerah wavelet. Besarnya pengaruh dari teknik diversity selection combining yang digunakan dapat diketahui melalui analisa PSNR. Hasil simulasi dari penelitian ini menunjukkan bahwa, adanya peningkatan perbaikan sistem dipenerima bila dibandingkan dengan tanpa menggunakan teknik diversity selection combining.
\end{abstract}

\section{Kata kunci : Diversity Selection Combining, Noise AWGN, Fading Rayleigh, PSNR, BER}

\begin{abstract}
This study is the simulation of SPIHT image compression using diversity selection combining techniques. The image is compressed by using SPIHT compression techniques after wavelet decomposition. By giving Rayleigh fading channel and AWGN on the channel transmission will cause the degradation of the overall system performance. To minimize the effects caused by the errors that occur during the transmission, the diversity selection combining techniques are used at the receiver that work on the wavelet domain in order to increase the overall system performance. Performance evaluation on the use of selection combining diversity technique can be determined through PSNR analysis. The simulation results of this study indicate that applying the diversity selection combining techniques on the system that affected by noise AWGN and Rayleigh fading can increase the performance of the overall system at the receiver when comparing to the receiver without using the selection combining diversity techniques.
\end{abstract}

Keywords : Diversity Selection Combining, Noise AWGN, Fading Rayleigh, PSNR, BER

Copyright $@ 2017$ JNTE. All rights reserved

\section{PENDAHULUAN}

Salah satu teknik sederhana dan efisien untuk mengatasi kerusakan sinyal informasi yang diakibatkan oleh adanya fading adalah dengan menggunakan teknik diversity. Teknik ini akan memanfaatkan propagasi acak dari gelombang radio, yaitu dengan penemuan metoda untuk membangkitkan dan mengekstrak lintasanlintasan sinyal independent [1-5],[9],[15].

Konsep diversity sangat sederhana yaitu jika satu lintasan gelombang radio mengalami gangguan yang disebabkan oleh fading, dimungkinkan ada lintasan-lintasan lainnya memiliki sinyal yang lebih bagus. Dengan banyaknya lintasan sinyal untuk dipilih, maka rata-rata SNR (signal to Noise Ratio) dapat diperbaiki pada bagian penerima [15].
Dalam sistem transmisi telekomunikasi, informasi berupa data, suara, citra dan video akan dikirim dari pemancar menuju penerima melalui sebuah kanal komunikasi. Kanal komunikasi secara real dapat berupa medium fisik (seperti dua pasang kabel, kabel koaksial, serta fiber optik yang menghubungkan antara pemancar dan penerima), maupun medium nonfisik (seperti medium udara berupa gelombang elektromagnetik yang dipancarkan dari pemancar ke penerima). Selama transmisi informasi melalui kanal komunikasi pasti akan selalu terjadi penurunan kualitas informasi. Penurunan kualitas informasi ini dapat disebabkan oleh berupa interferensi, delay spread, redaman (attenuation), derau (noise) serta timbul tenggelamnya sinyal informasi (fading) [9]. 
Pada medium non-fisik kanal wireless, gangguan yang paling dominan adalah adanya multipath fading. Multipath fading terjadi karena sinyal informasi yang dipancarkan akan tersebar kesegala arah melewati medium udara. Akibatnya sinyal yang sampai dipenerima adalah penjumlahan antara sinyal informasi dari arah path 1 , path 2 , path 3 dan seterusnya. Sehingga akan didapat sinyal yang saling mengurangkan dan bahkan saling menghilangkan akibat adanya perbedaan fasa yang tiba di penerima. Pengaruh dari gangguan dominan ini dapat menyebabkan kesalahan pendeteksian pada bagian penerima system telekomunikasi. Misalnya akibat pengaruh dari gangguan ini menyebabkan sinyal informasi yang dikirim bit '1' dapat berubah menjadi bit '0' yang diterima di bagian penerima begitupun sebaliknya, sehingga dengan demikian unjuk kerja sistem akan menurun di bagian penerima. Untuk mengatasi permasalahan di dalam transmisi informasi melalui kanal wireless ini, maka berbagai teknik yang dapat dikembangkan untuk memperbaiki kualitas sistem, salah satu dari teknik ini adalah teknik diversity selection combining. Teknik diversity ini diterapkan dibagian penerima dimana penerima memilih komponen sinyal yang paling baik dari berbagai path sinyal yang masuk ke penerima. Gambaran umum diversity selection combining dapat dilihat pada Gambar 1 dibawah ini.

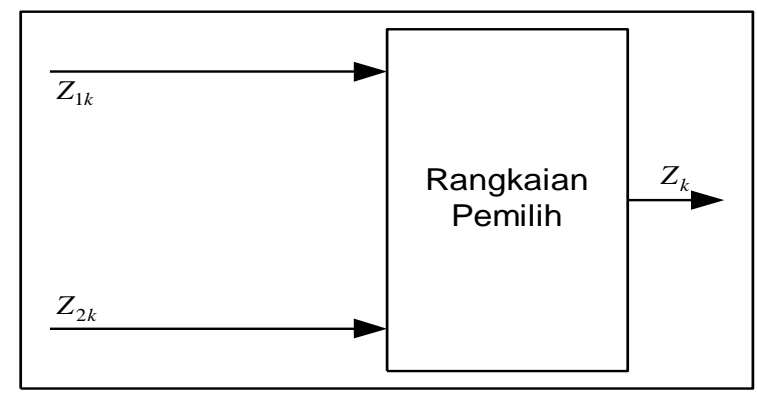

Gambar 1. Sistem umum diversity selection combining [15]

Nilai $Z_{k}$ diperoleh tergantung dari nilai inputan yang nilai SNR nya lebih besar. Hal ini dapat dijelaskan sebagai berikut: jika nilai $Z_{1 k}$ lebih besar dari nilai $Z_{2 k}$ maka nilai yang keluar dari penerima adalah sama dengan nilai $Z_{1 k}$ begitupun sebaliknya.

Teknik diversity sebagai salah satu cara untuk mengatasi fading dan noise pada transmisi melalui kanal wireless [2-5],[8]. Beberapa penelitian tentang transmisi citra melalui kanal wireless juga telah dilakukan antara lain [9] yang menggunakan teknik diversity yang berada pada domain wavelet untuk mendapatkan citra rekonstruksi yang baik. Pada transnmisi citra ini model kanal yang digunakan adalah two-state Gilbert-Elliott channel[6-7]. Turbo Codes [14] digunakan untuk melindungi citra selama transmisi dan teknik perlindungan data selama transmisi [11-12].

Pada penenelitian ini digambarkan suatu simulasi yang menerapkan teknik diversity selection combining pada penerima. Teknik Selection combining mengacu pada penelitian [3], [9]. Berdasarkan penelitian yang telah dilakukan diatas, maka dalam penelitian ini berjudul 'Analisa Unjuk Kerja Peningkatan Transmisi Citra Pada Kanal Wireless Menggunakan Teknik Diversity Selection Combining'. Penelitian ini menghasilkan peningkatan unjuk kerja transmisi citra pada kanal wireless bila menggunakan teknik diversity selection combining dibandingkan dengan tanpa sistem tersebut.

\section{TINJAUAN PUSTAKA}

\subsection{Noise AWGN}

Model kanal yang digunakan adalah Noise AWGN (Additive White Gaussian Noise). Noise ini berdistribusi normal dengan nilai rata-rata (mean) nol. Noise ini bernilai acak dan bersifat menambahkan sinyal aslinya. Bentuk persamaan pdf dari distribusi Gaussian adalah [13]:

$$
p(x)=\frac{1}{\sqrt{2 \pi} \sigma} e^{-\left(x-m_{x}\right)^{2} / 2 \sigma^{2}}
$$

dimana :

$\mathrm{x}=$ Variabel Acak

$m_{x}=$ mean

$\sigma^{2}=$ varians dari variable random

\subsection{Fading Rayleigh}

Pada kanal wireless, distribusi Rayleigh secara umum dipakai untuk menggambarkan statistik perbedaan waktu dari envelope yang diterima untuk sebuah sinyal flat Fading. Fading cepat merupakan Rayleigh Fading karena Fading ini terdistribusi mengikuti distribusi Rayleigh, yang mempunyai fungsi kepadatan 
probabilitas seperti yang ditunjukkan persamaan (2) [13].

$$
p\left(r_{a}\right)=\left\{\begin{array}{cc}
\frac{r_{a}}{\sigma^{2}} \exp \left(-\frac{r_{a}{ }^{2}}{2 \sigma^{2}}\right) & \left(0 \leq r_{a} \leq \infty\right) \\
0 & \left(r_{a}<0\right)
\end{array}\right.
$$

dimana :

$$
\begin{aligned}
& \sigma=\text { tegangan rata }- \text { rata } \\
& \sigma^{2}=\text { daya rata-rata }
\end{aligned}
$$

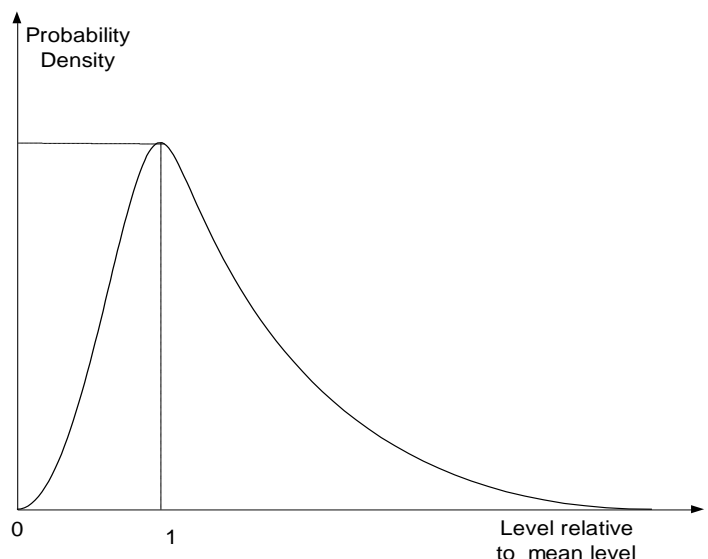

Gambar 2. Grafik PDF (Probability Density Function) Distribusi Rayleigh [13].

Fungsi distribusi kumulatif menyatakan presentasi lebih kecil dari nilai $R_{a}$ tertentu, yang diperoleh dengan melakukan integral terhadap fungsi rapat peluang $p\left(r_{a}\right)$.

$P\left(R_{a}\right)=P_{r_{a}}\left(r_{a} \leq R_{a}\right)=\int_{0}^{R_{a}} p\left(r_{a}\right) d r_{a}=1-\exp \left(-\frac{R_{a}^{2}}{2 \sigma^{2}}\right)$

$r_{a_{\text {mean }}}$ distribusi Rayleigh adalah :

$$
r_{a_{\text {mean }}}=E\left[r_{a}\right]=\int_{0}^{\infty} r_{a} p\left(r_{a}\right) d r_{a}=\sigma \sqrt{\frac{\pi}{2}}=1,2533 \sigma
$$

$\sigma_{r_{a}}^{2}$ merupakan varians dari distribusi Rayleigh yang mewakili daya ac pada selubung sinyal.

$$
\begin{aligned}
\sigma_{r_{a}}^{2} & =E\left[r_{a}^{2}\right]-E^{2}\left[r_{a}\right]=\int_{0}^{\infty} r_{a}^{2} p\left(r_{a}\right) d r_{a}-\frac{\sigma^{2}}{2} \\
& =\sigma^{2}\left(2-\frac{\pi}{2}\right)=0,4292 \sigma^{2}
\end{aligned}
$$

Untuk menghitung nilai tengah untuk $r_{a}$, dapat digunakan persamaan (4). $\frac{1}{2}=\int_{0}^{r_{a_{\text {median }}}} p\left(r_{a}\right) d r_{a} \Rightarrow r_{a_{\text {median }}}=1,177 \sigma$

Jadi terdapat perbedaan nilai rata-rata dan nilai tengah sebesar $0,55 \mathrm{~dB}$ dalam distribusi Rayleigh. Sebagai catatan bahwa nilai tengah pada prakteknya sering digunakan, karena data Fading biasanya diukur dilapangan dan kenyataannya distribusinya tidak dapat diasumsikan. Dengan penggunaan nilai tengah sebagai pengganti nilai rata - rata maka mudah kita membandingkan distribusi Fading yang berbeda dan memiliki nilai tengah yang bermacam-macam. Envelope sinyal Fading yang dibangkitkan merupakan proses kompleks gaussian yang mempunyai bagian real yang independen dengan bagian imajinernya. Pada Gambar 2 ditunjukkan grafik PDF (Probability Density Function) dari sebuah distribusi Rayleigh [13].

\subsection{Teknik Selection Combining}

Aturan dari diversity selection combining berdasarkan blok dan hanya memilih blok-blok bit, $b(l)$, dari satu bit stream didasarkan pada suatu ukuran $\omega(l)$, yang bergantung pada karakteristik transformasi wavelet, dan aturan ini dapat dilihat sebagai berikut [9]:

1. Aturan diversity combining untuk blok koefisien approksimasi.

Bila nilai blok koefisien approksimasi dari diversity kanal 1 lebih kecil dari nilai blok koefisien approksimasi dari diversity kanal 2, maka nilai blok koefisien approksimasi bernilai satu. Kemudian bila nilai blok koefisien approksimasi dari diversity kanal 1 lebih besar dari nilai blok koefisien approksimasi dari diversity kanal 2, maka nilai blok koefisien approksimasi bernilai min satu dan jika nilai blok koefisien approksimasi dari diversity kanal 1 sama dengan nilai blok koefisien approksimasi dari diversity kanal 2, maka nilai blok koefisien aproksimasi bernilai nol. Seperti pada persamaan (7) [9].

$$
h_{L}^{l}(i, j)=\left\{\begin{array}{cc}
1 & d_{1}(i, j)<d_{2}(i, j) \\
-1 & d_{1}(i, j)>d_{2}(i, j) \\
0 & c_{L 1}(i, j)=c_{L 2}(i, j)
\end{array}\right.
$$

2. Aturan diversity combining untuk blok koefisien detil 
Bila nilai blok koefisien detil dari diversity kanal 1 lebih kecil dari nilai blok koefisien detil dari diversity kanal 2, maka nilai blok koefisien detil bernilai satu. Kemudian bila nilai blok koefisien detil dari diversity kanal 1 lebih besar dari nilai blok koefisien detil dari diversity kanal 2, maka nilai blok koefisien detil bernilai min satu dan jika nilai blok koefisien detil dari diversity kanal 1 sama dengan nilai blok koefisien detil dari diversity kanal 2, maka nilai blok koefisien detil bernilai nol. Seperti pada persamaan (8) dibawah ini:

$$
h_{H}^{l}(i, j)=\left\{\begin{array}{cc}
1 & t_{1}(i, j)<t_{2}(i, j) \\
-1 & t_{1}(i, j)>t_{2}(i, j) \\
0 & c_{H 1}(i, j)=c_{H 2}(i, j)
\end{array}\right.
$$

3. Aturan pemilihan blok dari diversity combining dilakukan dengan cara :

Jika ukuran blok $\omega(l)$ lebih besar sama dengan nol, maka blok yang dipilih adalah blok $b_{1}(l)$, tetapi jika ukuran blok $\omega(l)$ lebih kecil dari nol, maka blok $b_{2}(l)$ yang dipilih. Seperti persamaan (9):

$$
b(l)= \begin{cases}b_{1}(l) & \text { Jika } \omega(l) \geq 0 \\ b_{2}(l) & \text { Jika } \omega(l)<0\end{cases}
$$

untuk $l=1,2, \ldots, L$ dimana

$\omega(l)=\sum_{\substack{(i, j) \in \text { lowres } \\ \text { subband }}} h_{L}^{l}(i, j)+\sum_{\substack{(i, j) \text { detail } \\ \text { subband }}} h_{H}^{l}(i, j)$ dan Ini adalah

nilai dari koefisien approksimasi

$d_{k}(i, j)=\left|c_{L k}(i, j)-c_{L k}(i, j+1)\right|$ dan ini

adalah nilai dari koefisien detil

$t_{k}(i, j)=\left|c_{H k}(i, j)-\left(\sum_{m=0}^{1} \sum_{n=0}^{1} c_{H k}(2 i+m, 2 j+n) / 4\right)\right|$

untuk $k=1,2$, $\mathrm{k}$ adalah cabang diversity

Dimana $l$ di mengacu pada blok ke- $l$ dari bitbit yang diterima dan $\omega(l)$ diperbaharui untuk setiap blok baru dari data.

\section{METODOLOGI}

Metode penelitian yang digunakan dalam penelitian ini adalah metode eksperimental. Penelitian eksperimental merupakan observasi di bawah kondisi buatan, dimana kondisi tersebut dibuat dan diatur oleh peneliti dan penelitian dilakukan dengan melakukan manipulasi terhadap objek penelitian serta adanya control [10].

\subsection{Sampel Penelitian}

Sampel penelitian yang digunakan adalah citra digital grayscale dengan kedalaman 8 bit dengan nama file Barbara.tif. Sampel tersebut merupakan standar internasional untuk penelitian citra. Citra grayscale digunakan untuk penelitian ini karena untuk citra grayscale tingkat komputasi yang dibutuhkan tidak terlalu tinggi dibanding citra RGB dan pada dasarnya dalam proses transmisi citra kedua jenis citra tersebut mempunyai karakteristik yang sama. Citra sampel mempunyai kedalaman 8 bit, yang berarti bahwa untuk masing-masing piksel pada citra sampel diwakili oleh nilai 8 bit yang bervariasi dari 0-255 sesuai dengan karakteristik citra tersebut.

\subsection{Desain Penelitian}

Penelitian dilakukan dengan merancang sebuah sistem transmisi citra seperti gambar di bawah ini:

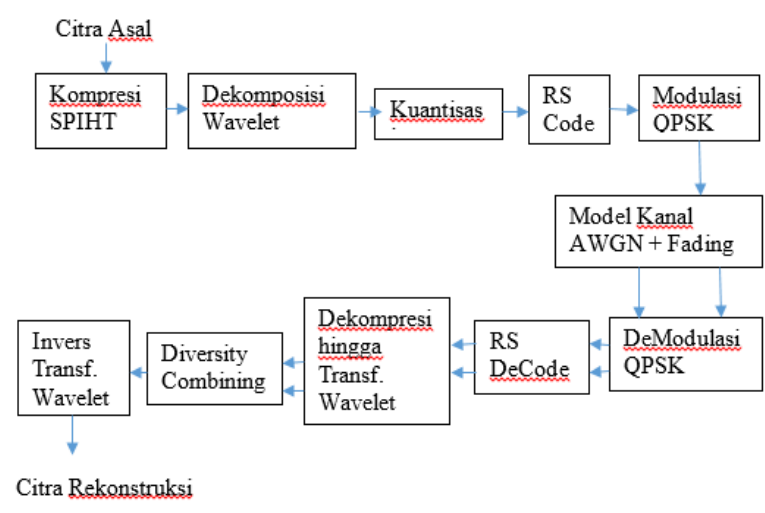

Gambar 3. Rancangan Sistem Transmisi Citra.

\subsubsection{Simulasi Kanal AWGN dan Fading Rayleigh \\ Pada sistem ini diasumsikan ada dua kanal} sehingga sinyal $y(t)$ yang masuk pada kedua kanal tersebut akan menjadi $y_{1}(t)$ dan $y_{2}(t)$. Besarnya sinyal $y_{1}(t)$ dan $y_{2}(t)$ adalah sinyal $y(t)$ dibagi akar dari jumlah kanal atau :

$$
y_{1}(t)=y_{2}(t)=0,707 \times y(t)
$$

Pada masing-masing kanal terdapat fading yang berdistribusi Rayleigh. Pengaruh dari fading ini akan merusak bentuk sinyal pada 
masing-masing kanal. Kemudian sinyal-sinyal yang terkena fading itu akan dipengaruhi pula oleh noise Gaussian $n_{1}(t)$ dan $n_{2}(t)$. Sinyal yang terkena fading dan noise ini selanjutnya masuk ke rangkaian matched filter integrated and dump guna mendapatkan sinyal dengan performansi yang lebih baik sehingga sinyal ini lebih menyerupai sinyal aslinya, dimana keluaran dari rangkaian ini yaitu $Z_{l k}$ dan $Z_{2 k}$ yang merupakan inputan untuk rangkaian combining. Proses pada rangkaian decision (Gambar1) adalah mendemodulasi sinyal keluaran dari rangkaian combining untuk memperoleh bit-bit yang diterima, selanjutnya dengan menggunakan metode Monte Carlo akan diprediksi besarnya BER (Bit Error Rate)

Noise yang dibangkitkan pada sistem ini berdistribusi normal dengan mean $\mu$ adalah nol dan varian $\sigma^{2}$ sebesar $N o / 2$.

$$
n_{k}(t) \sim N\left(0, \frac{N o}{2}\right)
$$

Besarnya varian dipengaruhi oleh harga $\mathrm{No}$ yang bervariasi sesuai dengan besarnya $S N R$ (Signal to Noise ratio) dan besar energi perbitnya $E b$. Hubungan dari parameterparameter ini ditentukan dengan persamaan :

$$
S N R=\frac{E b}{N o}
$$

Selain itu kanal juga dipengaruhi oleh fading yang memiliki distribusi Rayleigh. Envelope sinyal fading yang dibangkitkan merupakan proses kompleks gaussian yang mempunyai bagian real yang independen dengan bagian imajinernya.

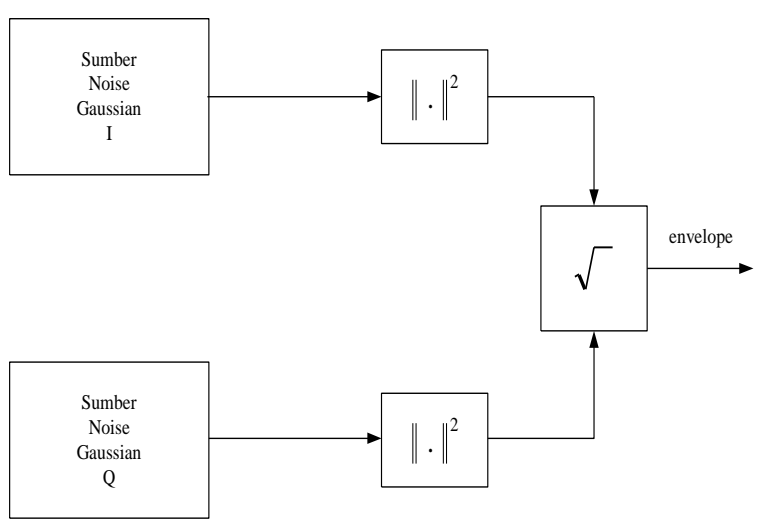

Gambar 4. Pembangkitan fading Rayleigh [15].
Pada kanal radio mobil, distribusi Rayleigh secara umum dipakai untuk menggambarkan statistik perbedaan waktu dari envelope yang diterima untuk sebuah sinyal flat fading. Fading cepat merupakan Rayleigh fading karena fading ini terdistribusi mengikuti distribusi Rayleigh. Metode untuk membangkitkannya diilustrasikan pada Gambar 4.

Dari Gambar 4 terlihat bahwa $I_{g}(n)$ dan $Q_{g}(n)$ adalah komponen in-phase dan quadrature dari proses kompleks gaussian. Langkah-langkah dalam pembangkitan envelop fading ini adalah :

$$
\begin{gathered}
I_{g}(n) \quad=\operatorname{randn}(1, \text { panjang sinyal input }) \\
Q_{g}(n)=\operatorname{randn}(1, \text { panjang sinyal input }) \\
\text { envelope }=\sqrt{I_{g}(n)^{2}+Q_{g}(n)^{2}}
\end{gathered}
$$

Fading merupakan karakteristik utama dalam propagasi radio bergerak. Fading dapat didefinisikan sebagai perubahan fasa, polarisasi dan level dari suatu sinyal terhadap waktu. Definisi dasar dari fading yang paling umum adalah yang berkaitan dengan mekanisme propagasi yang melibatkan refraksi, refleksi, difraksi, hamburan, dan redaman gelombang radio, Dari segi kualitas keberadaan fading dapat dirasakan sebagai timbul tenggelamnya suara yang terdengar dipenerima. Sinyal fading $r(t)$ merupakan gabungan dua komponen yaitu $r_{l}(t)$ dan $r_{o}(t), \quad r_{l}(t)$ disebut fading lambat, sedangkan $r_{o}(t)$ disebut fading cepat dengan persamaan:

$$
r(t)=r_{l}(t)-r_{o}(t)
$$

sedang fading cepat diperoleh dari :

$$
r_{o}(t)=r(t)-r_{l}(t)
$$

Fading lambat adalah rata-rata sinyal fading $r_{l}(t)$ yang juga disebut dengan local mean. Fading lambat disebabkan adanya perubahan konfigurasi alam antara base station dengan unit bergerak yang akan menyebabkan fluktuasi path loss (redaman lintasan) akibat efek bayangan dari penghalang alam. Fading lambat sering disebut dengan shadowing. Fading cepat sering disebut juga dengan multipath fading. Penyebab utama dari fading ini karena adanya lintasan ganda (multipath) akibat dipantulkannya gelombang oleh benda-benda 
seperti rumah, gedung, kendaraan, pohon dan benda-benda lain disekitar personal station yang menyebabkan sinyal menempuh suatu lintasan dari pemancar ke penerima. Selain itu Dengan adanya tambahan noise maka bentuk sinyal akan semakin rusak. Tipe fading ini merupakan tipe yang paling umum terjadi.

Karena perbedaan panjang lintasan yang ditempuh oleh lintasan pantul dan lintasan langsung, maka akan menyebabkan perbedaan amplitudo dan fasa dari kedua sinyal tersebut ketika diterima mobile station (MS). Dalam keadaan yang ekstrim dimana sinyal sama dan beda fasa $180^{\circ}$, maka sinyal akan saling meniadakan atau sinyal total adalah nol, sebaliknya bila fasanya sama, maka sinyal merupakan jumlah dari kedua sinyal yang datang tersebut.

Fading yang dibangkitkan dalam simulasi ini konstan sepanjang satu interval bit, dimana jumlah sampel fading yang dibangkitkan sama dengan jumlah bit input. Disamping itu nilai $r m s$ fading $E\left\{R^{2}\right\}$ adalah 1 , serta fadingnya hanya pada amplitudo sinyalnya saja.

Adanya fading akan mengganggu sinyal yang masuk ke masing-masing kanal, dimana yang terjadi berupa proses perkalian antara envelope fading dengan sinyal yang ditransmisikan. Dengan adanya tambahan noise maka bentuk sinyal akan semakin rusak, serta kemungkinan kesalahan bit atau simbol yang terdeteksi pada penerima akan semakin besar. Bentuk hubungan pengaruh fading dan noise terhadap sinyal dapat diekspresikan dengan persamaan :

$$
\begin{aligned}
& Z_{1}(t)=y_{1}(t) \cdot r_{1}(t)+n_{1}(t) \\
& Z_{2}(t)=y_{2}(t) \cdot r_{2}(t)+n_{2}(t)
\end{aligned}
$$

dimana: $y_{1}(t), y_{2}(t)$ adalah sinyal pada kanal 1 dan 2

$r_{l}(t), r_{l}(t)$ adalah fading pada kanal 1 dan 2

$n_{1}(t), n_{2}(t)$ adalah noise pada kanal 1 dan 2

\subsubsection{Rangkaian Decision}

Selection diversity merupakan teknik diversity combining yang paling sederhana. Pada teknik ini, penerima memilih sinyal yang paling baik, dalam hal ini sinyal SNR yang terbesar. Oleh karena itu untuk memilih sinyal dengan SNR yang terbesar dibutuhkan rangkaian decision. Pada rangkaian decision terjadi proses decoding guna mendeteksi bit-bit pada sisi penerima, proses ini dilakukan dengan suatu aturan. Aturan tersebut memberikan performansi yang optimum, sehingga dapat dikurangi kesalahan yang terjadi.

$$
b_{k}^{\prime}= \begin{cases}1, & \text { jika } A_{k}^{\prime} \geq 0 \\ 0, & \text { jika } A_{k}^{\prime}<0\end{cases}
$$

dimana :

$b^{\prime}{ }_{k}=$ Bit yang terdeteksi pada penerima

$A^{\prime}{ }_{k}=$ Keluaran dari rangkaian combining

\subsection{Variabel Penelitian}

Variabel-variabel yang digunakan pada penelitian berdasarkan klasifikasinya, adalah sebagai berikut:

1. Variabel independen, yang merupakan variabel yang dapat dimanipulasi. Variabel independen yang digunakan dalam penelitian ini adalah bit per pixel dan SNR.

2. Variabel dependen, variabel yang berubah berdasarkan perubahan nilai variabel independen. Variabel dependen yang digunakan dalam penelitian adalah PSNR (Peak Signal to Noise Ratio) dan BER (Bit Error Rate)[1-5], [15].

\subsection{Teknik Analisis Sistem}

Kinerja sistem yang disimulasikan dianalisis dengan menggunakan variabel dependen PSNR. PSNR dapat dirumuskan:

$$
P S N R=10 \bullet \log _{10} \frac{255^{2}}{\frac{1}{N} \sum_{i} \sum_{j}(p(i, j)-\hat{p}(i, j))^{2}}
$$

Dimana $p(i, j)$ merupakan nilai piksel citra yang asli, $\hat{p}(i, j)$ merupakan nilai piksel citra rekonstruksi, dan $N$ merupakan ukuran citra. Kinerja sistem juga dianalisis dengan BER (Bit Error Rate) dengan rumus:

$$
B E R=\frac{n}{N}
$$

Dengan : $\quad n=$ jumlah bit salah yang diterima $\mathrm{N}=$ jumlah bit yang diterima 


\section{HASIL DAN PEMBAHASAN}

Simulasi unjuk kerja sistem Transmisi Citra Terkompresi SPIHT (Set partitioning in hierarchical trees)[1] menggunakan Teknik Diversity Selection Combining dilakukan berdasarkan blok diagram pada Gambar 3 . Analisis dilakukan berdasarkan hasil dari simulasi yang telah dilakukan. Rasio kompresi yang diberikan adalah 0,6 bpp. Berikut ini merupakan tabel perbandingan nilai SNR, BER, dan PSNR citra Barbara pada rasio kompresi 0,6 bpp.

Tabel 1. Perbandingan Nilai BER dan PSNR Transmisi Citra Terkompresi SPIHT Menggunakan Teknik Diversity Selection dan Tanpa Teknik Diversity Selection Citra Barbara 0,6 bpp

\begin{tabular}{|c|c|c|c|c|}
\hline \multirow{2}{*}{$\begin{array}{c}\text { SNR } \\
(\mathbf{d B})\end{array}$} & \multicolumn{2}{|c|}{$\begin{array}{c}\text { Tanpa Diversity } \\
\text { Selection Combining }\end{array}$} & \multicolumn{2}{c|}{$\begin{array}{c}\text { Dengan Diversity } \\
\text { Selection Combining }\end{array}$} \\
\cline { 2 - 5 } & BER & $\begin{array}{c}\text { PSNR } \\
(\mathbf{d B})\end{array}$ & BER & $\begin{array}{c}\text { PSNR } \\
(\mathbf{d B})\end{array}$ \\
\hline 10 & 0,0857 & 5,6231 & 0,0274 & 12,7754 \\
\hline 12 & 0,0529 & 5,3653 & 0,0114 & 10,2869 \\
\hline 14 & 0,0214 & 13,0039 & 0,0011 & 15,6867 \\
\hline 16 & 0,0073 & 12,2488 & $9,537 \times 10^{-5}$ & 18,2252 \\
\hline 18 & 0,0013 & 13,1749 & $1,462 \times 10^{-4}$ & 20,8429 \\
\hline 20 & $5,726 \times 10^{-4}$ & 15,4959 & 0 & 28,7322 \\
\hline
\end{tabular}

Grafik perbandingan antara SNR dan BER juga SNR dan PSNR dari hasil simulasi dengan sampel citra Barbara ini dapat dilihat pada Gambar 5 dan 6.

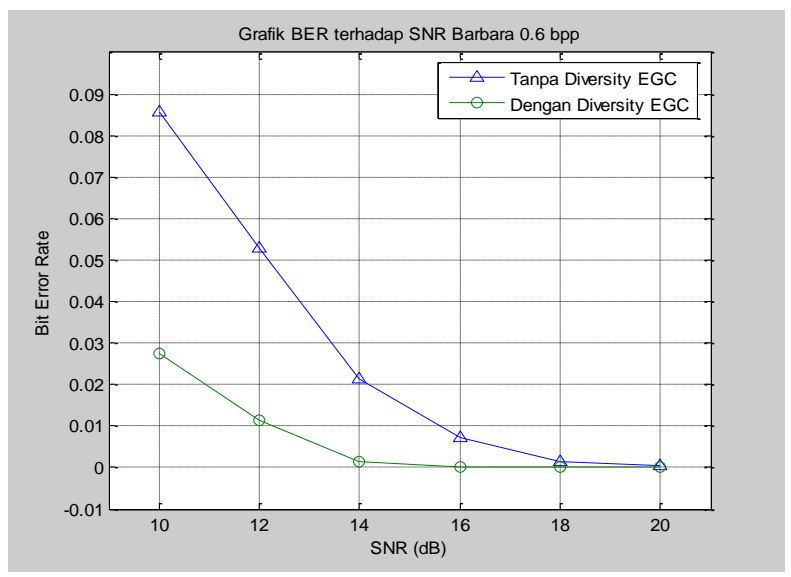

Gambar 5. Perbandingan BER Sistem Menggunakan Diversity Selection dan Sistem Tanpa Diversity Selection Citra Barbara dengan Rasio Kompresi 0,6 bpp

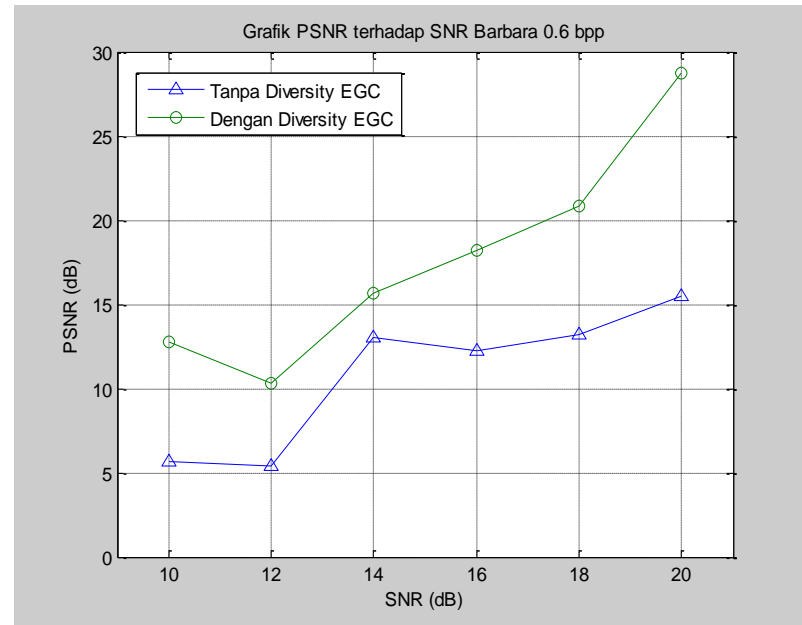

Gambar 6. Perbandingan PSNR Sistem Menggunakan Diversity Selection dan Sistem Tanpa Diversity Selection Citra Barbara dengan Rasio Kompresi 0,6 bpp

\begin{tabular}{|l|l|}
\hline $\begin{array}{c}\text { Tanpa Diversity } \\
\text { Selection Combining }\end{array}$ & \multicolumn{1}{|c|}{$\begin{array}{c}\text { Dengan Diversity } \\
\text { Selection Combining }\end{array}$} \\
\hline & \\
\hline SNR $=20 \mathrm{~dB}$ & $\mathrm{SNR}=20 \mathrm{~dB}$ \\
$\mathrm{Jumlah}$ bit salah diterima & Jumlah bit salah diterima \\
$=90$ & $=0$ \\
$\mathrm{BER}=5,7226 \times 10^{-4}$ & $\mathrm{BER}=0$ \\
$\mathrm{PSNR}=15,4959 \mathrm{~dB}$ & $\mathrm{PSNR}=28,7322 \mathrm{~dB}$ \\
\hline
\end{tabular}

Gambar 7. Perbandingan Citra Rekonstruksi Barbara antara Sistem Menggunakan Diversity Selection dan Sistem Tanpa Diversity dengan Rasio Kompresi 0,6 bpp dan SNR 20 dB.

Dari tabel dan grafik perbandingan di atas dapat dilihat pada SNR $10 \mathrm{~dB}$ pada sistem dengan diversity selection combining didapatkan nilai BER 0,0274 dan nilai PSNR 12,7754 dB, sedangkan sistem tanpa diversity Selection didapatkan nilai BER 0,0857 dan nilai PSNR 5,6231 dB. Dari hasil tersebut dapat dilihat peningkatan kinerja sistem dengan diversity selection dibandingkan dengan sistem tanpa diversity selection. Untuk nilai PSNR terjadi peningkatan 7,1523 $\mathrm{dB}$ dan untuk nilai BER terjadi penurunan 0,0583 . Peningkatan nilai PSNR terjadi untuk setiap nilai SNR dari $10 \mathrm{~dB}$ hingga $20 \mathrm{~dB}$ untuk sistem tanpa diversity 
Selection, sedang untuk sistem dengan diversity selection peningkatan nilai PSNR terjadi dari SNR $10 \mathrm{~dB}$ sampai $20 \mathrm{~dB}$. Penurunan nilai BER terjadi untuk setiap nilai SNR sampai nilai BER menjadi nol, yaitu terjadi pada SNR $20 \mathrm{~dB}$ untuk sistem dengan diversity Selection. Salah satu hasil subyektif untuk SNR $20 \mathrm{~dB}$ dapat dilihat pada Gambar 7.

Untuk citra Barbara pada rasio kompresi 0,6 bpp ini peningkatan nilai PSNR rata-rata adalah 6,9396 dB untuk nilai SNR dari $10 \mathrm{~dB}$ sampai 20 $\mathrm{dB}$. Untuk nilai BER didapatkan penurunan ratarata adalah 0,0214 .

\section{KESIMPULAN}

Berdasarkan hasil penelitian yang dilakukan, maka dapat diambil kesimpulan bahwa kenaikan SNR berimplikasi pada penurunan BER, namun tidak selalu meningkatkan nilai PSNR citra rekonstruksi. Hal ini disebabkan nilai PSNR tidak hanya tergantung pada jumlah bit error, tetapi terlebih pada letak bit error tersebut pada rangkaian bit. Kenaikan jumlah bit per pixel tidak berpengaruh pada nilai BER melainkan pada nilai PSNR citra rekonstruksi. Semakin besar bit per pixel, maka nilai PSNR akan bertambah besar. Pada citra Barbara 0,6 bpp ini terjadi peningkatan PSNR rata-rata sebesar $6,9396 \mathrm{~dB}$ dan penurunan nilai $\mathrm{BER}$ rata-rata sebesar 0,0214 .

\section{DAFTAR PUSTAKA}

[1]. A. Said \& W. A. Pearlman. (1996). A New, Fast, and Efficient Image Codec Based on Set Partitioning In Hierarchical Trees. IEEE Trans. Circuits Syst Video Technol., Vol. 6 pp. 243-250.

[2]. Baharuddin, (2005). Peningkatan Kualitas Transmisi Citra dengan Menggunakan Teknik Diversity Combining Metode Equal Gain Diversity. Jurnal Ilmiah Poli Rekayasa Vol.1, No 1, ISSN: 1858-3709.

[3]. Baharuddin, (2005). Transmisi Citra dengan Teknik Diversity pada Kanal Wireless. Thesis, Insitut Teknologi Sepuluh November.

[4]. Baharuddin, (2005). Peningkatan Unjuk Kerja Transmisi Citra Terkompresi Spiht Menggunakan Teknik Diversity Equal Gain Combining Pada Daerah Frekuensi Radio. Jurnal Saintek Vol X Nomor 1.
Terakreditasi, No. ISSN 1410-8070, pp. 95-106.

[5]. Baharuddin, (2016). Peningkatan Unjuk Kerja Sistem Transmisi Komunikasi Digital Pada Penerima Dengan Menggunakan Teknik Diversity Equal Gain Combining. Jurnal JNTE Vol. 5 No. 2. ISSN: 2302-2949

[6]. E. N. Gilbert, (1960). Capacity of a burstnoise channel. Bell System Technical Journal, pp. 1253-1265.

[7]. E. O. Elliott, (1963). Estimates of error rates for codes on burst error channels. Bell System Technical Journal, vol. 42, pp. 1977.

[8]. Hourani, Hafeth, (2005). An Overview of Diversity Techniques in Wireless Communication System. Helsinki University of Technology Communication Lab

[9]. Liane C. Ramac \& Pramod K. Varshney. (2000). A Wavelet Domain Diversity Method for Transmission of Images over Wireless Channels. IEEE Journal On Selected Areas In Communication, Vol. 18, No. 6. pp. 891-898

[10]. Nazir, Mohammad. (2011) Metode Penelitian. Jakarta: Ghalia Indonesia.

[11]. P.G. Sherwood \& K. Zeger. (1998). Error Protection for Progressive Image Transmission over Memoryless and Fading Channels. IEEE Trans. Commun., vol.46, pp. 1555-1559.

[12]. Sudhakar, R, Karthiga Ms R, \& Jayaraman. (2002). Image Compression using Coding of Wavelet Coefficients - A Survey. Department of Electronic and Communication Engineering, PSG College of Technology.

[13]. Theodore. S. Rappaport. (2002). Wireless Communication Principles \& Practice. Prentice-Hall. Communications Engineering and Emerging Technologies Series.

[14]. Thomos Nikolaos, Boulgouris Nikolaos V, \& Strinzis Michael G. (2005). Wireless Image Transmission Using Turbo Codes and Optimal Unequal Error Protection. IEEE Trans. On Image Processing Vol. 14. No.11. pp. 643-650.

[15]. Vijaya Chandran Ramasami. (2001). BER Performance Over Fading Channels and Diversity Combining, EECS 862 Project. 


\section{Biodata Penulis}

Baharuddin, adalah staf pengajar Jurusan Teknik Elektro Fakultas Teknik Universitas Andalas Padang. Lulus Program Sarjana pada tahun 1993 pada Bidang Teknik Telekomunikasi dan Elektronika Jurusan Teknik Elektro Fakultas Teknik Universitas Hasanuddin. Lulus program Master pada Bidang Teknik Telekomunikasi Multimedia di ITS Surabaya tahun 2005. 